\title{
Training programme for senior registrars in community paediatrics
}

\author{
A F COLVER, M J DANSKIN, J M PARKIN, F S ROGERS, AND J H WALKER \\ Regional Postgraduate Institute for Medicine and Dentistry, University of Newcastle upon Tyne
}

SUMMARY Consultant paediatricians with a special interest in community child health are being appointed in many parts of the United Kingdom but there are few training posts or programmes for this specialty. A training programme for senior registrars in the northern region that three doctors have completed and in which six doctors are currently engaged is presented.

The Court report envisaged an integrated health service for children in which primary care was strengthened and hospital paediatrics were less separate from community paediatrics. ${ }^{1}$ It recommended the appointment of consultant community paediatricians, and the need for such appointments is now agreed by the British Medical Association, the British Paediatric Association, and the Central Committee for Community Medicine and Community Health. ${ }^{2}$

The second Forfar Report highlighted the fact that many senior medical staff in community child health were not adequately trained or qualified. ${ }^{3}$ It described how suitably trained senior clinical medical officers might become consultant paediatricians with a special interest in community child health and proposed that junior staff should train to become consultant paediatricians in this specialty. Recently the specialist advisory committee (SAC) in paediatrics of the joint committee on higher medical training has drawn up an outline senior registrar training programme (Professor I B Houston, personal communication). Many health authorities are now appointing specialist consultants, but the realisation of their importance has come before many training posts have been created.

In 1982 the need to appoint to consultant posts in community paediatrics only those whose training was appropriate led to discussions between district medical officers, specialists in community medicine, and consultant paediatricians of the Newcastle, Northumberland, and North Tyneside health districts and the Departments of Child Health and Family and Community Medicine of the University of Newcastle upon Tyne. These resulted in a programme of higher professional training in community paediatrics that three doctors have now completed and in which six are currently engaged.

\section{Description of the training programme}

To be considered for the training programme applicants must have completed general professional training with at least three years postgraduate experience in hospital and community paediatrics and must usually hold the MRCP diploma. The training programme lasts four years; although some trainees whose previous experience is appropriate may require less, all are committed to at least two years of the programme. Four of the posts are funded by health districts that converted vacant clinical or senior clinical medical officer posts into training posts. The upper end of the clinical medical officer pay scale in fact corresponds to that of the senior registrar. Some trainees do on call work to match the extra salary a hospital senior registrar receives for this work. The other two posts are funded directly by the Department of Health and Social Security (DHSS) scheme for doctors with domestic commitments who wish to train part time.

COMPONENTS OF THE TRAINING PROGRAMME

Specialised training modules

Each module is supervised by a consultant in that

Table Specialised training modules and their duration

\begin{tabular}{lll}
\hline $\begin{array}{l}\text { Child psychiatry } \\
\text { Mental handicap }\end{array}$ & Full time & 6 Months \\
$\begin{array}{l}\text { Child development } \\
\text { centre }\end{array}$ & 2-3 Days per week & 6 Months \\
Orthopaedics & 2-3 Days per week & 6 Months \\
$\begin{array}{l}\text { Ophthalmology } \\
\text { Otology }\end{array}$ & 2 Days per week & 4 Months \\
Paediatric neurology & 2 Days per week & 4 Months \\
Epidemiology and & 1-2 Days per week & 4 Months \\
$\quad$ statistics & 20 Sessions & \\
\hline
\end{tabular}


specialty. The table shows the modules and how long they take. Those modules in child psychiatry, mental handicap, and assessment of handicapped children require the trainee to carry direct clinical responsibility for patients as a member of a consultant led team. Those in orthopaedics, ophthalmology, and otology give the trainee opportunities to observe children in clinics, to visit schools, to work with paramedical staff, and to study the conduct of screening programmes connected with those specialities. Training in epidemiology is provided through modules for trainees in community medicine.

\section{Research}

Each trainee must develop a major research project, which is usually supervised by a member of the university. Examples of projects so far include studies of bereavement reactions in children, infant colic, circumstances surrounding childhood deaths from asthma, impedance and orthoptic screening in preschool children, and the development of a preschool health surveillance programme.

Organisational and clinical work in a health district The trainee learns about services for children and the care of children in the community by having responsibilities within one health district. These vary between health districts and examples are listed as follows.

(i) Leading a team of clinical medical officer, senior house officer, school nurse etc, who are responsible for a geographically defined area within a district.

(ii) Membership of a district handicap team or equivalent.

(iii) Clinical responsibility for a group of children with special problems-for example, the partially hearing.

(iv) Membership of committees such as the Pre-School Playgroup Association, Home Start, Health Education, education, adoption, and fostering.

(v) Responsibilities for child abuse, supervised clinically by the specialist consultant paediatrician, and administratively responsible to the Area Review Committee.

(vi) The setting up of training programmes in health surveillance for family doctors and health visitors.

It is expected that some of these responsibilities will be carried throughout the four years of the training, while others will be assumed as time allows. The clinical work is supervised by a consultant community paediatrician if there is one in post or by a consultant paediatrician in conjunction with the specialist in community medicine (child health).
The organisational work is supervised by a consultant community paediatrician, a specialist in community medicine, or a district medical officer as appropriate.

\section{Hospital paediatric work}

A consultant community paediatrician will often have responsibilities in hospital; he or she may see new outpatients and refer some children from the community to hospital for investigation. Therefore, continuity and integration of care should be taught at senior registrar level. Currently half the trainees conduct a regular hospital outpatient clinic and may admit patients to hospital under the overall care of their supervising consultants. The others do not conduct a hospital clinic at present but it is clearly desirable that they do. Whether the trainee joins an on call rota will depend on the needs and previous experience of the individual. On completion of training all trainees must have had sufficient experience in acute paediatrics to be able to join a consultant on call rota if necessary.

\section{Discussion}

New ideas for improving the services and the care that children receive have created the need for training initiatives. One way of providing senior registrar training in community paediatrics is to incorporate a year of community experience into an existing hospital rotation. The alternative is to design a new post and programme. We favour the latter approach because we think that neither the necessary breadth and depth of experience nor the appropriate orientation to the work of community paediatrics can be provided in a single year away from hospital. To set up a new post there needs to be careful planning by paediatricians and community physicians and a willingness by health authorities to direct funds to this training. Conversion of a clinical or senior clinical medical officer post to a training post reduces the 'service' component. As already mentioned, however, the need for training results from the recognition of the need for new approaches to the delivery of the service. Therefore, time might occasionally be released by a development in the service-for example, by changing the emphasis placed on routine medical inspections in school. As well as a long term benefit, there is also an immediate benefit to the health districts that set up training posts, as these attract doctors of high quality, experience, and commitment.

Training for community paediatrics cannot develop in isolation and for training to be well received by health authorities, prove sustainable in terms of consultant supervision, and be valuable to the trainees certain criteria are necessary. 


\section{EFFECTIVE ADMINISTRATION}

A training committee should oversee the training programme. In our region, this is the Education Committee for Community Paediatrics of the Postgraduate Institute, with representatives from all health districts in the northern region, the university, and paediatrics. This committee also oversees the training of senior house officers in community paediatrics and clinical medical officers. Senior registrar training is thus part of an overall strategy for training in community paediatrics in the region.

\section{EFFECTIVE SUPERVISION}

This is required at many levels. Firstly, the SAC should inspect the posts, advise on improvements, and determine whether they meet national requirements. When our programme began the SAC could inspect only senior registrar posts. The regional registrar and senior registrar committee therefore granted honorary senior registrar status to our posts. We welcome the fact that the SAC will now also inspect senior clinical medical officer posts designated for training. Secondly, the regional education committee should interview trainees annually to discuss individual problems and progress. Thirdly, each trainee should have named supervisors for the clinical, organisational, and research parts of the training. The importance of effective supervision was well expressed by the SAC. 'It is important to appreciate that one of the basic differences between simply doing a job of work and receiving an education in it is the quality and quantity of discussion, advice, supervision and stimulation provided by the supervisors.' Fourthly, the senior registrars should themselves supervise or instruct others such as senior house officers, nurses, or paramedical staff in community paediatrics.

\section{COLLABORATION WITH SPECIALIST SUPERVISORS}

Organisers of the programme should listen to the comments of the consultant supervisors in the specialist modules on the progress of the programme and its relevance to that specialty. For example, the trainer in paediatric neurology found the module to be unsatisfactory because of conflicts between the complexity of the tertiary referral service and the trainee's need for clinical responsibility. This module needs to be redesigned.

THE INFORMAL CURRICULUM

Occasional meetings of the trainees, usually in the evening at one of their houses, enabled them to compare their experiences, discuss their training, and to arrange special tutorials by invited teachersfor example, on the subject of child abuse. Their discussions about training have helped to shape its format, ensure that, overall, it has been enjoyed and identify weaknesses. One trainee thought that more time should be devoted to formal training in communication skills. Another trainee thought that the training did not sufficiently emphasise a sociological view of health nor the importance of community work in improving child health. Another trainee thought that her organisational and clinical work in a health district was not properly supervised.

The training programme emphasises core components that every trainee must complete. This both sets a standard and imposes an obligation on health authorities to ensure that sufficient time and money are available for these. The programme, however, does not specify every topic that could be included in community paediatric training. The senior registrars are already experienced paediatricians and must have time to develop their own special interests in depth.

As the importance of the role of the consultant community paediatrician is recognised and authorities attempt to implement the recommendation that there should be at least one consultant in this branch of paediatrics in each district, there will inevitably be a shortage of those whose training has specifically prepared them for such a post. Under these circumstances authorities may be tempted to appoint candidates whose training or experiences is less than adequate. We believe this would be misguided, for the quality of service at secondary care level in the community envisaged by the Court report can only be achieved if the consultant community paediatrician is both perceived by others and him or herself to be a paediatrician whose training has fully prepared him or her for that role. Such training must now be seen as an urgent national priority.

We thank Dr T Berney, consultant child psychiatrist; Dr DP Foster, senior lecturer in community medicine; Dr D GardnerMedwin, consultant paediatric neurologist; Dr E Ellis and Dr MT Gibson, consultants in developmental paediatrics; $\mathrm{Mr} \mathrm{J}$ Howe, consultant ophthalmologist; Professor I Kolvin, child psychiatrist; Mr M Leonard, consultant orthopaedic surgeon; and Mr RT Watson, consultant otologist for their supervision of the specialist training modules. We thank Mr A Holmes, assistant registrar to the Postgraduate Institute, for help given to the Education Committee and also Mrs Anne Robinson for her preparation of the manuscript.

\section{References \\ 1 Committee on Child Health Services. (Court Report) (Cmnd. 6684). Fit for the future. London: HMSO, 1976. \\ 2 Report of the Child Health Forum. BMA annual report of council 1986/1987. Br Med J 1987;294:appendix II:34-6. \\ 3 Training of senior clinical medical officers in child health. Joint Paediatric Committee of the Royal Colleges of Physicians and the British Paediatric Association. (Second Forfar Report.) Br Med J 1982;285:955-6.}

Correspondence to Dr AF Colver, Beaconhill Children's Centre, 163 Langdale Drive, Cramlington NE23 8EH.

Received 20 August 1987 